\title{
Side Light: Reflections in a Mirror. A Meditative Exegesis
}

In 1974, the Dutch Pandora Foundation (Stichting Pandora), which aims to improve the position of people with psychological and psychiatric problems in society, and which works actively against prejudices, published a poster with a slogan that translates as "Have you ever met a normal person? So... did you like it?" Graphic designer Frans van der Aa had the Dutch text, a quote from the famous zoth century writer Simon Carmiggelt, printed on reflective paper. The poster was widespread in the Netherlands, decorated many walls, doors and windows, and the slogan became famous, almost to the level of reaching proverb status. Even today, one can occasionally still run into it (Stichting Pandora to this day has sold the poster in their web shop); I recently did, in the bathroom of a café in the city of Amsterdam.

The effect of the mirror paper is that spectators see their own faces when reading the text and, as a result, are challenged to wonder whether they themselves have really got both paddles in the water. What is 'normal'? What is the difference between 'them' and 'us'? What do these people say about me? The poster reflects both the complexity and the effectiveness of a mirror in the public sphere: it is empathically intended to make people wonder, raise questions, and reflect upon their understandings, and it implicitly invites them to reconsider or even change their ideas about and behaviour towards other people. It doesn't just aim to present people with their mirror image, this is not the final goal: more than this, it expresses a desire to move beyond the categories of normal and abnormal. The mirror symbolises an anacrusis to a further and deeper yearning.

A mirror also pops up in one of the writings of Paul the Apostle, in his first letter to the Corinthians. Towards the end of Chapter 13, which is often understood as an ode to love, Paul contrasts our current seeing in a mirror with a future seeing face to face: "For now we see in a mirror, dimly, but then we will see face to face. Now I know only in part; then I will know fully, even as I have been fully known". (1 Cor. 13:12). The Greek word here translated with 'dimly' is ainigma: a riddle or puzzling saying. In the Septuagint, this word is also used in describing a divine meeting, namely when God is said to speak to Moses, "face to face - clearly, not in riddles" (Numeri 12:8). By using this word in his letter, Paul stresses "the present, imperfect and partial character of man's 


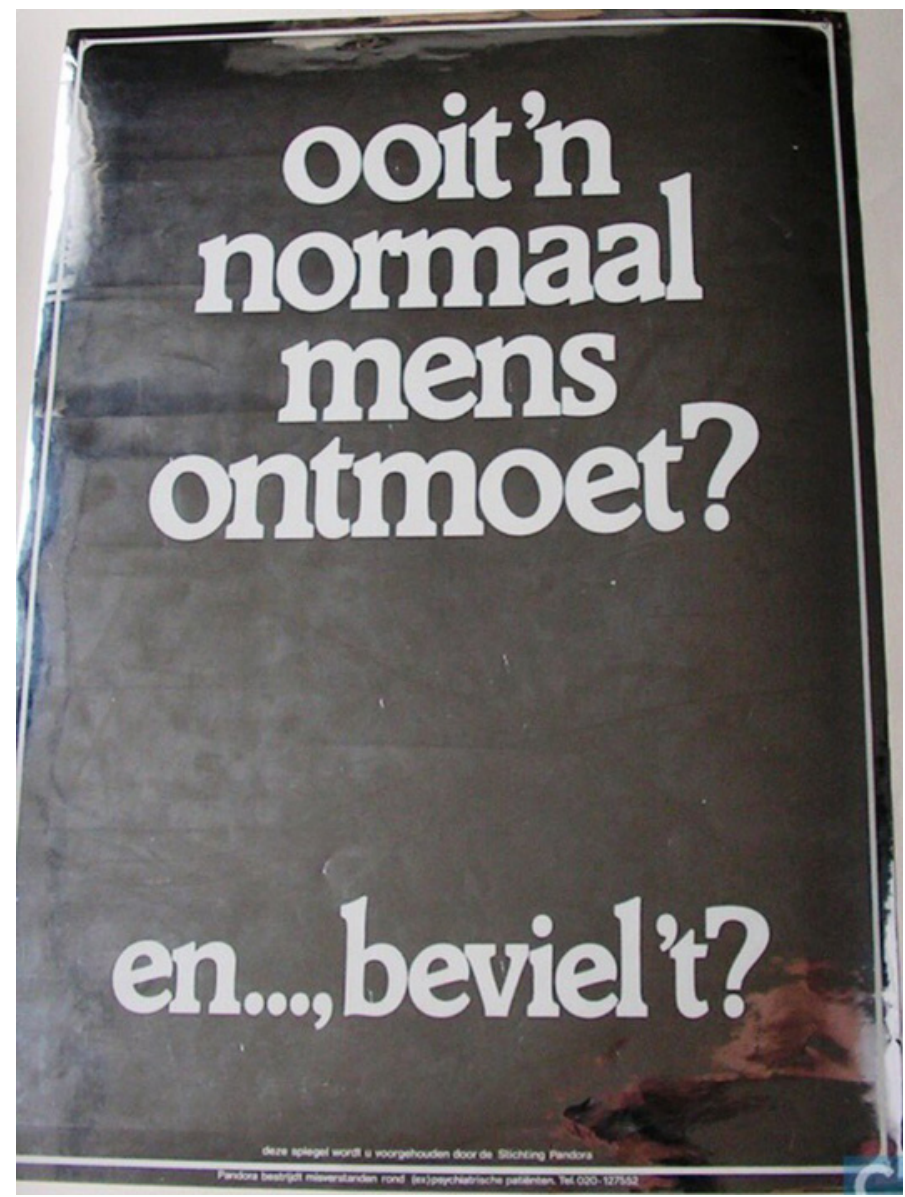

FIGURE 13 Poster for the Pandora Foundation

knowledge or vision of God". The point that he seems to be making here is not concerned so much with exactly what it is that we see in the mirror, but rather

1 Harm Hollander, "Seeing God 'in a riddle' or 'face to face'. An Analysis of 1 Corinthians 13.12", Journal for the Study of the New Testament 32, no. 4 (2010), 395-403, here 397. DoI: 10.1177/ 0142064X10365115. Hollander corrects the older idea that the mirror refers to an obscure image: "Most modern interpreters of 1 Cor. 13 correctly assume that the mirror imagery does not allude to the quality of seeing, in the sense that in Paul's view the image of God that we have is obscure or distorted. It rather refers to the indirect nature of looking into a mirror, in the sense that the apostle wanted to underline that man's vision and knowledge of God and the divine world is indirect: we see no more than the image of God". Hollander, "Seeing God", 397 . 
with the way that we see: indirect, mediated, incomplete. ${ }^{2}$ In a mirror we only see a reflection, an image of the thing, and not the thing itself. This contrasts with a direct way of seeing, with a knowing and understanding that is clear and complete. Biblical scholars have suggested that Paul intends to outline a difference between the type of knowing that is related to the gifts of the Spirit and a type of knowing that is eschatological and thus complete. The latter is God's own way of knowing. ${ }^{3}$

Like posters, public events can also function as a mirror. In The Passion, one can see, as in a mirror, a reflection of society's self-understanding. Paul's letter to the Corinthians suggests that one could also see, in The Passion, a reflection of how God understands society, of how God fully knows and understands us a reflection that is (still) indirect, imperfect, partial, and incomplete, but which is nevertheless real. From Moses, Paul derives the hope, desire and expectation that complete knowledge will one day also be granted to us - that we will know directly, fully, completely, and share in God's way of knowing.

This hope, desire and expectation may be an incentive to take public events like The Passion seriously for their potential to mirror fragments of the divine. Could this then be true: that the status reversal of a young man of disrepute who was typecast for the role of Barabbas is a fragmented example of God flipping the order of our reality, because God fully knows us? Could uncertainties and polarisations regarding our national identity as reflected in an event like this also reflect a deeper desire to share in a more-complete knowledge that moves beyond our incomplete categories of right or wrong, good or bad? Could it reflect a craving, a further yearning after divine knowledge? To understand ourselves like we are fully understood?

21 Corinthians 13:9 has already mentioned this partial and ephemeral knowing, which may be understood both in a quantitative (fragmented) as well as a qualitative (fuzzy) sense. Cf. Joseph Fitzmeyer sJ, First Corinthians. A New Translation with Introduction and Commentary, The Anchor Yale Bible (New Haven: Yale University Press, 20o8), 497-498.

3 See e.g. Gordon Fee, The First Epistle to the Corinthians, The New International Commentary on the New Testament (revised edition) (Grand Rapids: Eerdmans 2014). 